\title{
Analysis of treatment of comorbidities and the profile of medical consultations for diabetes mellitus
}

\author{
Análise do tratamento das comorbidades \\ e do perfil de consultas médicas do diabetes mellitus
}

Camilo Molino Guidoni ${ }^{1}$

Anna Paula de Sá Borges ${ }^{2}$

Osvaldo de Freitas ${ }^{2}$

Leonardo Régis Leira Pereira ${ }^{2}$

${ }^{1}$ Departamento de Ciências Farmacêuticas, Centro de Ciências da Saúde,

Universidade Estadual de Londrina. Av. Robert Koch 60 , Vila Operária. 86.038-350 Londrina PR. camiloguidoni@yahoo.com.br ${ }^{2}$ Faculdade de Ciências

Farmacêuticas de Ribeirão

Preto, Universidade de São

Paulo.

\begin{abstract}
The scope of this paper was to analyze the profile of medical consultations and drugs used for the treatment of comorbidities in patients with diabetes attended in the Brazilian Unified Health System. This was a pharmaco-epidemiological crosssectional study conducted between March 2006 and February 2007 All patients with diabetes attended in the western sanitary district of Ribeirao Preto in the state of São Paulo were included in the study. The types of medical attendance (primary, secondary and emergency care) and the drugs prescribed for the treatment of comorbidities were analyzed. The drugs were classified according to the Anatomical Therapeutic Chemical Classification System and 3,198 patients were identified. The mean age was 60.4 years and more than $55 \%$ of the patients were 60 years or older. The cardiovascular drugs most used were captopril or enalapril (60\%). About $40.6 \%$ of the patients used acetylsalicylic acid in platelet antiaggregant doses. The patients had an average of 5.1 medical consultations per year (primary care, secondary care and emergency care). The utilization of statins and acetylsalicylic acid was less than that reported in the literature and the data indicate a high prevalence of admission to emergency care.
\end{abstract}

Key words Unified Health System, Diabetes mellitus, Diabetes complications, Pharmaco-epidemiology, Primary health care
Resumo Analisar o perfil de consultas médicas e de medicamentos para o tratamento de comorbidades em pacientes com diabetes atendidos no Sistema Único de Saúde. Estudo farmacoepidemiológico e transversal realizado de mar/2006 a fev/ 2007. Foram incluídos no estudo portadores de diabetes atendidos no Distrito Sanitário Oeste de Ribeirão Preto (SP), sendo analisadas as consultas médicas realizadas na atenção primária, secundária e emergência, além dos medicamentos prescritos para tratamento de comorbidades associadas ao diabetes. Foram identificados 3.198 pacientes, com idade média de 60,4 anos e aproximadamente $55,0 \%$ idosos. Os medicamentos do sistema cardiovascular foram os mais prescritos, sendo que $60,0 \%$ dos pacientes utilizavam captopril ou enalapril. Além disso, 40,6\% dos pacientes faziam uso de ácido acetilsalicílico em dose antiagregante plaquetário. Em relação às consultas médicas, os pacientes apresentaram média de 5,1 visitas ao ano, na atenção primária, na atenção secundária e no atendimento de emergência. A utilização de ácido acetilsalicílico e estatina foram menores do que a relatada na literatura e os dados indicam uma alta prevalência de admissão no atendimento de emergência.

Palavras-chave Sistema Único de Saúde, Diabetes mellitus, Complicações do diabetes, Farmacoepidemiologia, Atenção Primária à Saúde 


\section{Introduction}

The Diabetes mellitus (DM) is one of the most prevalent chronic non-communicable diseases in the world with estimates of 438 million individuals with diabetes in $2030^{1}$. Besides the high prevalence, this disease presents continuous progression and is highly associated with comorbidities such as hypertension, obesity, dyslipidemia, among other ${ }^{2}$.

Concerning of the comorbidities treatment, it is important to emphasize that non-pharmacological treatment is essential in the care of comorbidities. However, if non-pharmacological treatment does not lead to acceptable disease control, the care of the disease must be completed by the administration of drugs. Therefore, it is essential that patients have access to a continuous and adequate drug to control the comorbidities. Thus, the increasing number of subjects diagnosed with DM suggests that it is necessary to study and understand the profile of drugs employed for comorbidities treatment.

Moreover, patients with DM have increased risk for micro and macrovascular complications, especially when they have inadequate control of the disease, being among the leading causes of ophthalmic complications, cardiovascular disease, peripheral vascular disease, endocrine/metabolic complications, renal complications and amputations $^{1,3}$. In addition, patients with DM have higher use of hospital inpatient care, outpatient and physician office visits, emergency care, visits with other health professionals, and drug prescription and medical supply use than patients without $\mathrm{DM}^{3}$.

Therefore, the patient with DM requires continued monitoring at different levels of health care and drug treatment for diabetes and comorbidities care. Thus, this study aimed to analyze the drugs utilization for comorbidities treatment and the profile of medical consultations of patients with DM attended by the Brazilian Public Health System.

\section{Casuistic and methods}

\section{Settings and Subjects}

This was a pharmacoepidemiological study of a cohort of patients with DM. The study was performed in the west sanitary district of the city of Ribeirao Preto (SP), which comprises a population of about 140000 inhabitants and 8 health units. Selection was realized through the database and were included all patient of the district mentioned above who received at least one of the oral antidiabetic drug (OAD) (glibenclamide 5mg; metformin $850 \mathrm{mg}$; gliclazide $80 \mathrm{mg}$ ) or insulin from Brazilian Public Health System between March 2006 and February 2007.

\section{Data source and data analyses}

\section{Database}

Retrospective cross-sectional data were collected through the database that belongs to health municipal secretariat of Ribeirao Preto (SP), which includes all information on medical prescriptions issued and consultations by Brazilian Public Health System of the municipality of Ribeirao Preto-SP. The information of this database refers to patient identification, gender, age, generic drug name, drug dispensing date, dose regimen, amount of drug dispensed, health unit where the drug dispensing was made, physicians and other health professionals appointments and attendance date. The drugs are dispensed monthly by health unit pharmacies upon presentation of drug prescriptions and are simultaneously registered in the database.

\section{Analysis of drugs}

Patients identified through the database were divided into five groups according to the therapeutic regimens used to DM treatment: 1 oral antidiabetic drug (1OAD), 2 oral antidiabetics drugs (2OAD), 1 oral antidiabetic drug plus insulin (1OAD plus INS), 2 oral antidiabetics drugs plus insulin (2OAD plus INS) e insulin (INS).

Drugs used to comorbidities treatment associated with DM were classified according to the first classification level of the Anatomical Therapeutic Chemical (ATC) Classification System of the World Health Organization and related to the respective study groups described above. It is worth noting that the drugs glibenclamide, gliclazide, metformin and insulin were not included in the anatomical therapeutic group of the alimentary tract and metabolism because they are part of the inclusion criteria of the study.

\section{Analysis of consultation}

Patients with DM had access to different levels of health care and it was possible to calculate the average number of visits for the five study groups. It is important to emphasize that the health care levels were divided in primary care, secondary care and emergency care. The visits in 
primary care were divided into subgroups by physicians (general practitioner, obstetrician/gynecology and pediatrics) and non-physicians professionals (pharmacists, nurses and other); the visits in secondary care were divided into subgroups by qualified physicians (endocrinologist, cardiologist, ophthalmologist, others) and nonphysicians professionals (psychologists, occupational therapists, others).

\section{Ethics and approvals}

The research project was approved by the Ethics in Research Committee of the Health Training Center of the Faculty of Medicine of Ribeirao Preto (SP), University of Sao Paulo.

\section{Statistical Analysis}

Statistical package for Social Sciences ${ }^{\circledR}$ (SPSS, version 11.5, 2002) and Microsoft Excel® (Microsoft Corporation, 2007) were used for data entry and analysis. The ANOVA and the Student t test whenever applicable were used to test the difference between means and the chi-square to compare two or more proportions. Statistical significance was considered for $\mathrm{p}<0.05$.

\section{Results}

Prescriptions by health unit pharmacies in the west sanitary district were analyzed for dispensation of OAD and insulin in the study period leading to the identification of 3918 patients. In this study, we found that most of the patients used monotherapy for the DM treatment. Furthermore, as expected, patients who used insulin in monotherapy had lower median and the lowest mean age of the study (Table 1 ). In addition, in relation to age, it is important to emphasize that $55.0 \%$ of patients were 60 years or older ${ }^{4-6}$.
Regarding anatomical classes of the drugs used in the present study, it is important to emphasize that the diseases of cardiovascular system are the most prevalent among patients with DM (Table 2).

Among the drugs of cardiovascular system, approximately $60.0 \%$ of patients used an angiotensin converting enzyme inhibitor (captopril or enalapril), followed by hydrochlorothiazide (37.4\%) and lipid modifying agents (lovastatin or simvastatin) (26.0\%). Propranolol was used by $16.4 \%$ of patients, being that $85.2 \%$ of them used insulin secretagogue or insulin or were elderly or both.

In relation to other anatomical classes, it is important to emphasize that $40.6 \%$ of patients used acetylsalicylic acid in antiplatelet doses (100 $\mathrm{mg} /$ day). In addition, $42.3 \%$ of men $>50$ years of age and $47.1 \%$ of women $>60$ years of age that used antihypertensive drugs or lipid modifying agents or both used acetylsalicylic acid in antiplatelet doses.

In addition, this study analyzed the number of visits in primary care, secondary care and emergency care performed by patients with DM (Table 3).

It is important to emphasize that the patients had an average of 4.2 visits per year with physicians including primary care and secondary care.

In relation to secondary care, the average number of visits with qualified professional per year was 0.20 endocrinologists, 0.18 cardiologists, 0.13 ophthalmologists, 0.07 nephrologists and 0.04 neurologists.

\section{Discussion}

As expected, the profile of patients with DM in this study is consistent with the profile of chronic non-communicable diseases patients ${ }^{7-8}$, with a

Table 1. Age group profile, gender and number of patients with Diabetes mellitus in each study group.

\begin{tabular}{lcccccc}
\hline & \multicolumn{5}{c}{ Therapeutics groups } \\
\cline { 2 - 6 } Parameters & 1OAD & 2OAD & 1OAD plus INS & 2OAD plus INS & INS & Total \\
\hline $\begin{array}{l}\text { Patients (\%) } \\
\text { Gender }\end{array}$ & $2216(56.6)$ & $1121(28.6)$ & $330(8.4)$ & $120(3.1)$ & $131(3.3)$ & 3918 \\
$\quad$ Female (\%) & 60.6 & 58.7 & 64.2 & 67.5 & 67.2 & 60.8 \\
Age (years) & & & & & & \\
$\quad$ Mean (SD) & $60.4(13.7)$ & $61.2(12.0)$ & $61.8(12.8)$ & $60.7(11.3)$ & $51.2^{*}(20.3)$ & $60.4(13.5)$ \\
Median & 61.0 & 62.0 & 62.0 & 61.0 & 54.0 & 61.0 \\
\hline
\end{tabular}

" $\mathrm{p}<0.05$ compared to the other therapeutics groups. OAD: Oral antidiabetic drug; INS: Insulin. SD = Standard Deviation. 


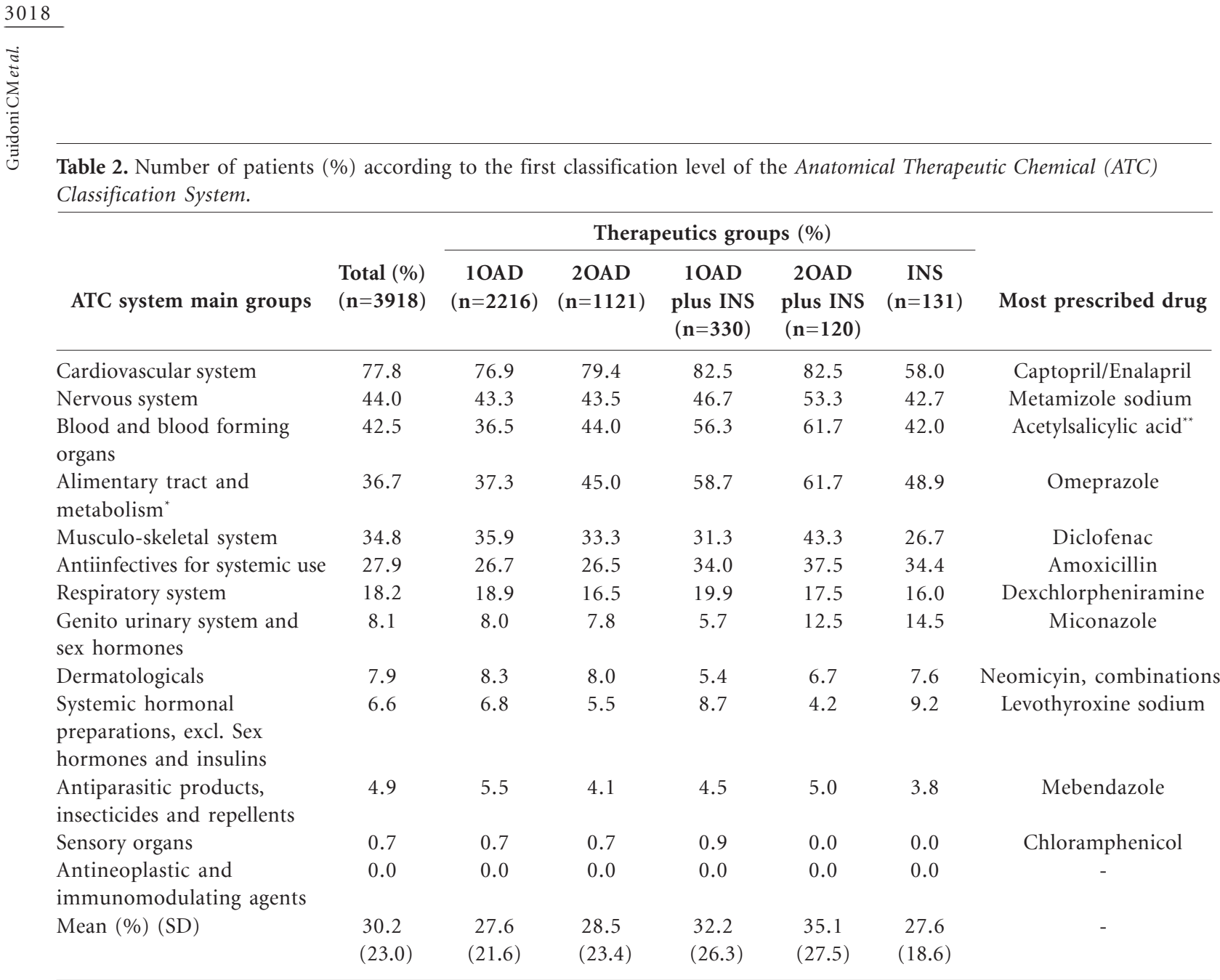

* It was disconsidered oral antidiabetics drugs and insulin. ${ }^{* *}$ Acetylsalicylic acid was used in antiplatelet doses (100 mg/day). OAD: Oral antidiabetic drug; INS: Insulin. SD = Standard Deviation.

Table 3. Number of visits per patient per year for each therapeutic group according to primary care, secondary care and emergency care.

\begin{tabular}{|c|c|c|c|c|c|c|}
\hline \multirow[b]{2}{*}{ Levels of care } & \multirow[b]{2}{*}{$\begin{array}{c}\text { Total } \\
(\mathbf{n}=3918)\end{array}$} & \multicolumn{5}{|c|}{$\begin{array}{c}\text { Number of visits per patient per year } \\
\text { for each therapeutic group }\end{array}$} \\
\hline & & $\begin{array}{c}\text { 1OAD } \\
(n=2216)\end{array}$ & $\begin{array}{c}\text { 2OAD } \\
(n=1121)\end{array}$ & $\begin{array}{c}\text { 1OAD } \\
\text { plus INS } \\
(n=330)\end{array}$ & $\begin{array}{c}\text { 2OAD } \\
\text { plus INS } \\
(\mathrm{n}=120)\end{array}$ & $\begin{array}{c}\text { INS } \\
(n=131)\end{array}$ \\
\hline \multicolumn{7}{|l|}{ Primary care } \\
\hline Physicians & 2.8 & 2.8 & 3.0 & 2.6 & 3.0 & 2.0 \\
\hline Non-physician professionals & 1.5 & 1.4 & 1.7 & 1.4 & 2.0 & 2.6 \\
\hline \multicolumn{7}{|l|}{ Secondary care } \\
\hline Qualified physicians & 1.4 & 1.3 & 1.4 & 1.6 & 1.1 & 1.1 \\
\hline Non-physician professionals & 0.3 & 0.4 & 0.4 & 0.5 & 0.4 & 0.3 \\
\hline Emergency care & 0.9 & 0.9 & 0.9 & 0.9 & 1.0 & 1.1 \\
\hline Total & 6.9 & 6.8 & 7.4 & 7.0 & 7.5 & 7.1 \\
\hline
\end{tabular}

OAD: oral antidiabetic drug; INS: Insulin.

predominance of patients aged 60 years or older. In addition, the insulin therapeutic group had the lowest age possibly due to the presence of patients with DM type 1 (Table 1).
According to the American Diabetes Association (2011) and Brazilian Society of Cardiology (2010), the hypertension treatment in patients with DM should include angiotensin converting 
enzyme inhibitor or angiotensin receptor antagonist $^{2,9}$, which was observed in this study (Table 2). It is important to emphasize that compared with other drugs of cardiovascular system, propranolol was the fourth most prescribed. This drug should be used with caution in these subjects, especially elderly patients or patients that use insulin secretagogue or insulin, since it can mask the symptoms of hypoglycemia ${ }^{2}$.

The therapy with acetylsalicylic acid in doses of 75-162 mg/day should be considered for primary prevention of cardiovascular events in patients at high risk of cardiovascular disease, which include most men over 50 years of age and women over 60 years of age with the presence of additional risk factors ${ }^{2}$. Despite evidence of efficacy of acetylsalicylic acid, it is still under utilized in patients with $\mathrm{DM}^{10}$, as observed in this study.

Regarding the treatment of dyslipidemia in patients with DM, statin therapy should be added in patients with high cardiovascular risk or with 40 years of age or more and presence of cardiovascular risk factors ${ }^{2}$. Sheng et al. ${ }^{11}$ and Jaffiol $^{12}$ found in the use of statins in $68.5 \%$ and $47.0 \%$ of patients with DM, respectively, higher than that found in present study.

Therefore, the use of drug for comorbidities treatment associated with DM is similar in all five therapeutics groups (1ADO, 2ADO, 1OAD plus INS, 2OAD plus INS, INS), demonstrating the standardization in care provided to patients with DM, regardless of age or therapeutic group.

In relation to outpatient care provided to patients with DM, it is known that patients with satisfactory control of the disease can be assessed by the multidisciplinary team every three or four months, and the investigation of chronic complications should be perform annually ${ }^{13,14}$. According to American Diabetes Association, it is necessary to perform the glycosylated hemoglobin test at least two times a year in patients who have stable glycaemic and quarterly in patients whose therapy has changed or who are not meeting glycaemic goals ${ }^{2}$. In this study, patients had average number of consultations/year according to the recommended, with no statistical difference between the therapeutics groups (Table 3 ). However, this number was $50.0 \%$ lower than found by Detournay et al. ${ }^{15}$ in France.

It is important to emphasize that the attendance in primary care represented the majority of health care to patients with DM in this study, similar to that found by Jaffiol ${ }^{12}$ and Brez et al. ${ }^{16}$. In study by Jaffiol ${ }^{12}$, most patients are treated by general practitioners (93.0\%), while $20.0 \%$ are fol- lowed by a diabetologist. However, visits with physicians in the primary care sometimes are challenged in relation to patient needs, since DM is a chronic disease of continuous progression. In the present study, patients with DM had reduced number of visits per year to qualified physicians.

In study by Monnier et al. ${ }^{17} 38.1 \%$ of patients were seen by a specialist at least once and $23.9 \%$ of patients were referred by their general practitioner to a private office. Even so, $45.6 \%$ of patients exhibited glycaemic hemoglobin above $8 \%$. In study by Mielczarski et al. ${ }^{18}, 58.1 \%$ of patients had glycosylated hemoglobin over $8.0 \%$, even so referring to an average of three annual consultations with doctors. Other studies showed that patients with diabetes followed up by endocrinologist showed poor glycaemic control ${ }^{19,20}$. In addition, literature reported that only $37.0 \%$ of patients with DM maintain adequate disease control ${ }^{21}$. Although the patients in this study presented an average of visits/year within recommended by the Brazilian Health Ministry, the average visits/year to endocrinologist become preoccupying since it is considerably lower than previously reported in literature.

According to American Diabetes Association ${ }^{2}$ and Brazilian Diabetes Association ${ }^{22}$, eye exams should be performed annually, it may be less depending on the degree of retinopathy found, or greater, as directed by the ophthalmologist. In study by van Dijk et al. ${ }^{23}, 27.5 \%$ of patients newly diagnosed DM and only 11.6\% known DM patients were seen by ophthalmologists. This result is considerably similar that found in the present study, where only $13.3 \%$ of patients had a consultation with a qualified physician (data not shown).

Regarding the assessment of renal function and symptoms of autonomic neuropathy, screening should begin after 5 years of type $1 \mathrm{DM}$ and at the diagnosis of type $2 \mathrm{DM}^{2,24,25}$. In study by Mielczarski et al (2012), 13.5\% of kidney problems were due to DM, being the average time from diagnosis of the disease of six years ${ }^{18}$. Therefore, the average visits/year with a neurologist and nephrologist in the present study are considerably lower than those recommended by the National Kidney Foundation and American Diabetes Association.

It is important to emphasize that the microvascular and macrovascular complications are among the major causes of high morbidity and mortality associated with $\mathrm{DM}^{2}$. In study by Grimaldi et al. ${ }^{26}$, cardiac and vascular complications were the most frequently observed. On the other hand, in the same study, $50.0 \%$ of patients 
were seen by cardiologist, value 2.8 times higher than that found in the present study.

Nevertheless, diabetes and comorbidities care has improved, but fewer than 1 in 4 patients with DM receives the minimum preventive care of at least one glycaemic haemoglobin test, at least 1 lipid test, and at least 1 glycaemic testing strip each year, reflecting the need for better assessment of these patients ${ }^{27}$. Therefore, analyzing the average physician consultations in the present study, note that it would be necessary take five years for all patients in the present study to have at least one visit with an endocrinologist. This situation is aggravated when we evaluate other qualified physicians such as cardiologist, ophthalmologist, neurologist, nephrologist, among others, important medical specialties in the management and prevention of major complications of DM. On the other hand, patients with DM had emergency care admission at rate of five times higher than with the qualified physicians (Table 3 ).

It is important to emphasize that primary care is important to the management and care of chronic diseases, with the level of optimal health care in which patient should be followed up. According to Prentice et al. (2011), patients with DM that have long waiting time between visits in primary care had the worst glycaemic outcomes when compared to patients that have short waiting time in access to health care services ${ }^{28}$. In the study by Borges et al. ${ }^{20}$, the patients who were followed up monthly with the pharmacist in primary care had better control of diabetes and decreased number of admission in the emergency care attendance.
The DM patients require continuous monitoring because it is a chronic and degenerative disease. In addition, poor glycaemic control and deterioration of diabetes are related to the addition of drugs, and more frequent professional monitoring. According to Durso (2006), DM is an area where individualized therapy is considered particularly relevant ${ }^{29}$. Thus, it was expected that patients with polytherapy or insulin alone present a greater number of consultations in different levels of health care compared with patients on monotherapy. However, as shown in Table 3, there is no statistical difference among the therapeutics groups. Therefore, patients in the five treatment groups (1ADO, 2ADO, 1OAD plus INS, 2OAD plus INS, INS) showed the same profile of care at different levels of health care, which may be due to standardization in care, as described above, or the difficulty of access to health care.

About the limitations of this study, the database does not provide clinical diagnosis and clinical laboratory results. However, this study has a fast and low cost methodology, which facilitates management of the high number of patients. The study was developed in a health district with 140000 inhabitants, a population size representative of hundreds of Brazilian cities. The computerized databases also are low cost systems allowing management and analysis of drug use at municipal, state and federal levels. To our knowledge, is the first study that correlates the levels of care used by patients with DM versus therapeutics groups for the DM treatment. 


\section{Collaboration}

CM Guidoni, APS Borges, O Freitas and LRL Pereira worked in the design, research, methodology, data analysis and interpretation, final draft and critically revising the article.

\section{Acknowledgements}

The authors thank Conselho Nacional de Desenvolvimento Científico e Tecnológico (CNPq) for the Master Degrees Scholarship awarded to Camilo Molino Guidoni. They also thank Dr. Pablo Diniz for collaboration in the development of the software that helped in the selection and arrangement of information of the database. Thank Ribeirao Preto-SP city for allowing the access to database.

\section{References}

1. International Diabetes Federation. Diabetes Atlas. $4^{\text {th }}$ Edition. Brussels: International Diabetes Federation; 2009.

2. American Diabetes Association. Standards of Medical Care in Diabetes. Diabetes Care 2011; 34(1):S11S61.

3. American Diabetes Association. Economic Costs of Diabetes in the U.S. in 2007. Diabetes Care 2008; 31(3):1-20.

4. Organização Mundial da Saúde (OMS). Envelhecimento ativo: uma política de saúde. Brasília: Organização Pan-Americana da Saúde (OPAS); 2005.

5. Brasil. Lei no 57, de 23 de setembro de 2003. Dispõe sobre o Estatuto do Idoso e dá outras providências. Diário Oficial da União 2003; 23 set.

6. Brasil. Decreto $\mathrm{n}^{\circ} 1.948$ de 4 de janeiro de 1996. Regulamenta a Lei $\mathrm{n}^{\circ} 8.842$, de 4 de janeiro de 1994, que dispõe sobre a Política Nacional do Idoso, e dá outras providências. Diário Oficial da União 1996; 4 jan.

7. Borges APS, Guidoni CM, Freitas O, Pereira LRL. Economic evaluation of outpatients with type 2 diabetes mellitus assisted by a pharmaceutical care service Arq Bras Endocrinol Metab 2011; 55(9):686-691.

8. Leite-Cavalcanti C, Rodrigues-Gonçalves, MC, RiosAsciutti LS, Leite-Cavalcanti A. Prevalência de doenças crônicas e estado nutricional em um grupo de idosos brasileiros. Rev Saude Publica 2009; 11(6):865-877.

9. Sociedade Brasileira de Cardiologia. VI Diretrizes Brasileiras de Hipertensão. Arq Bras Cardiol. 2010; 95(1):1-51.

10. American Diabetes Association. Aspirin therapy in diabetes (Position Statement). Diabetes Care 2004; 27(Supl.):S72-S73.

11. Sheng X, Murphy MJ, MacDonald TM, Wei L. Effect of statins on total cholesterol concentrations and cardiovascular outcomes in patients with diabetes mellitus: a population-based cohort study. Eur I Clin Pharmacol 2012; 68(8):1201-1208.

12. Jaffiol C. Current management of type 2 diabetes in France. Bull Acad Natl Med 2009; 193(7):1645-1661.

13. Brasil. Ministério da Saúde (MS). Secretaria de Políticas de Saúde. Departamento de Ações Programáticas Estratégicas. Plano de reorganização da atenção à hipertensão arterial e ao diabetes mellitus: hipertensão arterial e diabetes mellitus / Departamento de Ações Programáticas Estratégicas. Brasília: MS; 2001.

14. Brasil. Ministério da Saúde (MS). Secretaria de Atenção à Saúde. Departamento de Atenção Básica. Diabetes Mellitus / Ministério da Saúde, Secretaria de Atenção à Saúde, Departamento de Atenção Básica. Brasília: MS; 2006.

15. Detournay B, Cros S, Charbonnel B, Grimaldi A, Liard F, Cogneau J, Fagnani F, Eschwège E. Managing type 2 diabetes in France: the ECODIA survey. Diabetes Metab 2000; 26(5):363-369.

16. Brez S, Rowan M, Malcolm J, Izzi S, Maranger J, Liddy C, Keely E, Ooi TC. Transition from specialist to primary diabetes care: a qualitative study of perspectives of primary care physicians. BMC Fam Pract 2009; 10:39. 
17. Monnier L, Grimaldi A, Charbonnel B, lannascoli F, Lery T, Garofano A, Childs M; Mediab. Management of French patients with type 2 diabetes mellitus in medical general practice: Report of the Mediab observatory. Diabetes Metab 2004; 30(1):35-42.

18. Mielczarski RG, Costa JSD, Olinto MTA. Epidemiology and organization of health services: diabetes mellitus in a community of the city of Porto Alegre. Cien Saude Colet 2012; 17(1):71-78.

19. Correr CJ, Pontarolo R, Wiens A, Rossignoli P, Melchiors AC, Radominski R, Fernandez-Llimós F. Economic evaluation of pharmacotherapeutic follow-up in type 2 diabetes mellitus patients in community pharmacies. Arq Bras Endocrinol Metabol 2009; 53(7):825-833.

20. Borges AP, Guidoni CM, Ferreira LD, de Freitas O, Pereira LR. The pharmaceutical care of patients with type 2 diabetes mellitus. Pharm World Sci 2010; 32(6):730-736.

21. Saydah S, Fradkin J, Cowie CC. Poor control of risk factors for vascular disease among adults with previously diagnosed diabetes. JAMA 2004; 291(3):335342.

22. Sociedade Brasileira de Diabetes (SBD). Tratamento e acompanhamento do Diabetes mellitus. Diretrizes da Sociedade Brasileira de Diabetes. São Paulo: SBD; 2006.

23. Van Dijk CE, Verheij RA, Hansen J, Van der Velden L, Nijpels G, Groenewegen PP, de Bakker DH. Primary care nurses: effects on secondary care referrals for diabetes. BMC 2010; 10(230):1-9.

24. Craig KJ, Donovan K, Munnery M, Owens DR, Williams JD, Phillips AO. Identification and management of diabetic nephropathy in the diabetes clinic. Diabetes Care 2003; 26(6):1806-1811.

25. National Kidney Foundation. KDOQI ${ }^{\mathrm{TM}}$ Clinical Practice Guidelines and Clinical Practice Recommendations for Diabetes and Chronic Kidney Disease. National Kidney Foundation: Boston; 2006.

26. Grimaldi A, Grangé V, Allannicc H, Passad P, Rodiere M, Cornet P, Duprat I, Duc-Dodon P, Lemaire $\mathrm{A}$, Liard $\mathrm{F}$, Eschwège E. Epidemiological analysis of patients with Type 2 diabetes in France. J Diabetes Complications 2000; 14(5):242-249.

27. United State Renal Data System. USRDS 2005 Annual Data Report: Atlas of End-Stage Renal Disease in the United States, National Institutes of Health, National Institute of Diabetes and Digestive and Kidney Diseases. United State Renal Data System: Bethesda; 2005.

28. Prentice JC, Fincke BG, Miller DR, Pizer SD. Outpatient wait time and diabetes care quality improvement. Am J Manag Care 2011; 17(2):e43-54.

29. Durso SC. Using clinical guidelines designed for older adults with diabetes mellitus and complex health status. JAMA 2006; 295(16):1935-1940.

Artigo apresentado em 19/03/2012

Aprovado em 10/05/2012

Versão final apresentada em 28/05/2012 